\title{
Investigating the Relationship between the Organizational Agility and the Components of Resistive Economy in Isfahan's Department of Education
}

\author{
Seyyed Ali Siyadat \\ Faculty Member of Isfahan University \\ Farideh Yusefi \\ Master of Education Management
}

Doi:10.5901/mjss.2016.v7n3s3p279

\begin{abstract}
The aim of this study is to investigate the relationship between the organizational agility and the components of resistive economy in Isfahan's department of education. This study's population includes all administrative staffs of Isfahan's department of education (865 persons) who served in academic year of 2014-2015. The sample was estimated 298 persons based on Morgan table. The questionnaires were distributed among the administrative staffs of Isfahan's department of education in six districts of Isfahan City by stratified sampling method that 287 of them were analyzed. The methodology is descriptivecorrelation. In this study, the organizational agility inventory with 13 items and the resistive economy inventory with 17 items were used in the form of 5-point Likert scale. The content validity of the questionnaires was confirmed by the management experts. Their structure validity was confirmed by confirmatory factor analysis and their reliabilities was estimated by Cronbach's Alpha that they were obtained equal to 0.902, 0.936 for the variables of the organizational agility questionnaire and the resistive economy questionnaire, respectively. The results showed that there is a significant relationship between the organizational agility and the components of resistive economy in Isfahan's department of education.
\end{abstract}

Keywords: organizational agility, resistive economy, Isfahan's department of education

\section{Introduction}

Today, the organizations face with rapid changes which force them to adapt and choose selectively. Rapid technological changes, the increase of the risks, globalization and privatization expectations are of the environmental features which today organizations face with. To work in such environment, different strategies, including re-engineering, lean manufacturing, total quality management and employee empowerment, have been provided. One of the methods being used in recent decades is organizational agility.

In today's turbulent world, focusing on organizational agility is the best and newest way for survival and success of the organizations. Organizational agility is an informed and comprehensive response to changing needs in competitive markets and to achieve success by the opportunities that the organization obtains (Yaghoubi, Shokri, Rahat delmordeh, 2012).

Agility is a concept which can be a main factor in order to treat and manage the organizational environment with continuous changes and be associated with uncertainty and can help the organizations to achieve their preset goals (Aghaei \& Aghaei, 2014). Goldman et al. (1995) defined the agility as an ability of economic growth in a competitive environment characterized by permanent and unexpected changes. Agility is an organizational capability that should be considered to achieve mentioned goals by the managers. In fact, an agile organization is an organization which has features such as innovation, flexibility and readiness to respond to environmental changes and also is very robust and stable in facing with problems and shortcomings. Such organization achieves mentioned features with the minimum cost and energy (Desouza \& Roy, 2010). According to Sharifi \& Zhang (1999), agility means the ability of an organization to understand and predict existing changes in the work environment. Such organization must be able to detect the environmental changes and consider them as the growth and prosperity factors. Elsewhere, they defined agility as the ability to overcome unexpected challenges to face with unprecedented treats of work environment and achieve advantages and benefits from the changes as the opportunities for growth and development (Chen \& Chiang, 2011). Brain Maskell (2001) defined agility as the ability to flourish and boost in an environment which has permanent and unpredictable changes. In this regard, the organization should not be afraid of changes in their work environment and avoid them, but also, they should consider them as the opportunities to gain competitive advantage in the marketplace. Vernadat (1999) believed that the agility can be defined as the close alignment of the organization with the work changing 
needs in order to gain competitive advantage. In such organization, the employees' goals are aligned with the goals of organization and both of them seek the proper responses to the changing needs of the customers. The agile organizations try to reach the point in which their staffs know themselves and their colleagues are responsible for the results of their works at all levels (not just consider themselves in the fixed posts and as the responsible for doing the duties of those posts). In agile organizations, human resources are the main sources of operation. In such organizations, the employees are expected to understand the goals of organization at all levels of organization, be customer-oriented, be responsible for the success of the organization, be world-class expert in their careers, have innovation in their works, participate in the continuous improvement of key processes, make the right decisions quickly, carry out their duties effectively, participate in inter-agency teams whenever and wherever necessary (Hamel, Gary \& Prahalad, 1994).

Kidd noted one of the most comprehensive definitions of organizational agility as follows:

Agile organization is a fast, consistent and informed business which has ability to adapt quickly in response to unexpected and unforeseen evolutions and events, market's opportunities and customer's needs. In such business, the processes and structures are found that facilitate and speed the conformity and strength, it has a coordinated and systematic organization which has the ability to achieve competitive performance in the very dynamic and unpredictable business environment and of course, this environment is not disproportionate to the current functions of the organization (Kidd, 1994).

Two general definition of the agile organization are as follows:

1. An agile organization cannot be destroyed simply by sudden changes and events.

2. An agile organization is fast, consistent and powerful and responds to sudden changes, new opportunities of the market and customer's needs quickly.

Agile organizations are designed to understand and predict the changes in the business environment and in this regard, they restructure themselves (Aghaei, 2013).

Given the importance and the need for agility in the organization in unstable conditions and also, the department of education is one of the important organizations of Iran, it should become agile organization that the adversities and unstable conditions don't impact on it negatively and it can take advantage of unstable conditions.

If Iran, with its material and spiritual talents, rich and diverse resources, expanded infrastructure and especially, highly qualified manpower with the determination to progress, obeys the indigenous and scientific economic model derived from Islamic and revolutionary culture which is resistive economy, not only it will overcome all economic problems and defeat the enemy, which arrays against Iran by imposing a full-scale economic war, and force it to retreat, but also, it will realize the equitable, endogenous and extroverted, dynamic and progressive economy based on knowledge and technology and materialize inspiring model of an Islamic economic system in a world where risks and uncertainties caused by events outside authority, such as financial, economic, political, crises, are rising by keeping country's achievement in various fields and perpetuating the development and realizing the ideals and principles of constitution and 20-year vision plan (Supreme leader, 2013). Resistive economy implies that economic pressures by hostile forces hinder the development of the country that must be overcome. These pressures on the department of education are debatable from two aspects: one aspect relates to external pressures that are main caused sanctions and soft war in the current situation and the second one relates to internal pressures that are considered as the factors inhibit the implementation of the macro policies of education. As supreme leader mentioned as the guidelines for the implementation of resistive economy, popularizing economy by implementing the general policies of Article 44 and empowering the private sector, reducing dependence on oil, managing consumption, maximum use of time, resources and facilities and moving on schedule and avoiding sudden changes in laws and policies are the main factors that if they are not realized, department of education cannot resist on its way to deal with sanctions and it will go awry (Political information Center, 2012). So, if resistive economy is implemented in all organization, especially governmental organizations such as the organization of education, properly, not only the current sanctions and pressures will not damage the country but also lead to the development of it. Resistive economy is a term which was discussed firstly in meeting between the supreme leader and a group of entrepreneurs in 2010 by the supreme leader and then, it was also emphasized in several speeches. In fact, resistive economy implies the economy which has the ability to cope with shocks on the economy. Such economy must be flexible in different situations and have the ability to pass from crisis. To achieve this, it is necessary that there is a long-term look at economic policy and economic infrastructure should be designed in a way that general economic framework will be strengthened against all kinds of adversities. Also, according to the current conditions of the economy and imposed international sanctions, specific policies should be adopted that are sometimes different from the policies for normal conditions. Resistive economy needs to recognize the resources, both material and human resources, and use them. Resistive economy refers to the economic system of the nation or resistant social group who fights in accordance with their rights or the pursuit of political objectives which are right in the viewpoint of them. The more the economy of the 
nation or resistant social group help them in order to achieve the goals of resistance, the more resistance it is (Darvishzadeh and Beheshtifar, 2013).

Torabzadeh, Jahromi, Sajadieh and Samiei nasab (2013), in their article entitled "the dimensions and components of resistive economy of Islamic Republic of Iran in the view point of Ayatollah Khamenei", tried to extract the conceptual model from his remarks on the dimensions, characteristics and requirements of resistive economy by analyzing the supreme leader's speeches and using Grounded Theory. Saboktakin and Jafari (2013) studied the social factors influencing the students' attitudes to lifestyle which is commensurate with resistive economy (case study: the students of Karaj City). This research is conducted by survey method and using the questionnaire made by researcher. The questionnaires were distributed among 650 students of Karaj City. The results showed that the tendency of students to lifestyle which is commensurate with resistive economy has significant correlations with the variable of using the media, the consumerism of the family, religious socialization, the school's commitment to a culture of resistive economy and advanced social character. Regression analysis revealed that more than 30 percent of the dependent variable can be predicted by the variables of using the media, the consumerism of the family, religious socialization and advanced social character. Generally, the role of factor influencing the process of socialization, the tendency to the lifestyle which is commensurate with resistive economy, is more prominent. Abbas abad arabi, Babaeianpour and Fekri (2014), in their article entitled "the conceptual model of resistive economy with an emphasis on agility model of organizations", studied the need for agile organizations in order to achieve the general policies of resistive economy and proposed agile resistive economy by considering the literature of resistive economy and agility. Also, the conceptual model of agile resistive economy was proposed to achieve agile resistive economy that based on it, the agile resistive economy can be achieved by making organizations agile.

Given mentioned text above, the variable of organizational agility is of the effective variables to achieve a good organization to realize the twentieth paragraph of the policies of resistive economy issued by the supreme leader and also given the important role that the department of education plays in the future of children, adolescents and young adults and given to the economic conditions to achieve the goals of organization, if the resistive economy and organizational agility are implemented efficiently, they will play important roles in achieving the goals of education.

In this study, the relationship between the components of resistive economy and the agility of the department of education was studied by defining the components of resistive economy in the department of education so that the management issues and challenges, which the department of education faces with them to achieve the goals of resistive economy, are determined in addition responding to the orders of the supreme leader. So, now, the main issue is that how much does the organizational agility impact on achieving the component of resistive economy in Isfahan's department of education?

\section{Methodology}

Since the purpose of this study is to explore the relationship between the variables of organizational agility and the components of resistive economy, this study is in term of the goal and is descriptive-correlational in terms of gathering data. This study is descriptive because it describes the situation of the variables and the relationships between them. It is correlational because it tests and explains the relationships between the variable by using regression analysis.

This study's population includes all administrative staffs of Isfahan's department of education who served in academic year of 2014-2015, it includes 865 persons. The sample was estimated 298 persons based on Morgan table. The questionnaires were distributed among the administrative staffs of Isfahan's department of education in six districts of Isfahan City by stratified sampling method that 287 of them were analyzed. Table 1 shows the population and sample according to the 6 districts of Isfahan's department of education.

Table 1: Population and sample of the districts of Isfahan's department of education

\begin{tabular}{|l|c|c|c|c|}
\hline Work place & Number of employee & Population (\%) & Sample & Sample (\%) \\
\hline District 1 & 66 & 7.6 & 25 & 8.7 \\
\hline District 2 & 100 & 11.56 & 35 & 12.2 \\
\hline District 3 & 120 & 13.88 & 33 & 11.5 \\
\hline District 4 & 120 & 13.88 & 41 & 14.3 \\
\hline District 5 & 140 & 16.2 & 47 & 16.4 \\
\hline District 6 & 69 & 7.98 & 22 & 7.7 \\
\hline Department of education & 250 & 28.9 & 84 & 29.3 \\
\hline Total & 865 & 100 & 287 & 100 \\
\hline
\end{tabular}


In this study, two questionnaires were used to collect the required data.

Organizational agility inventory (Sharifi \& Zhang 1999). This questionnaire was designed with 13 items in 1999 by Sharifi \& Zhang to measure the organizational agility. It measures 4 dimensions of accountability, competence, flexibility and speed based on 5-point Likert scale.

Resistive economy inventory. It designed by the researcher to measure the realization of resistive economy in the organization. It has 17 items and measures 4 dimensions of organizational capacity, the relationship between employees and managers, control of the consumption and use of domestic production based on 5-point Likert scale. 4 mentioned dimensions were adopted from the article by Arabi (2013) in which the Supreme Leader's remarks were investigated. Table 2 shows the items related to the variables and their dimensions separately.

Table 2: Dimensions of organizational agility and resistive economy

\begin{tabular}{|l|l|c|c|}
\hline Variable & Dimension & Number of questions & No. of items \\
\hline \multirow{4}{*}{ Organizational agility } & accountability & 3 & $1-3$ \\
\cline { 2 - 4 } & competence & 6 & $4-9$ \\
\cline { 2 - 4 } & flexibility & 2 & $10-11$ \\
\cline { 2 - 4 } & speed & 2 & $12-13$ \\
\hline \multirow{4}{*}{ Resistive economy } & organizational capacity & 6 & $1-6$ \\
\cline { 2 - 4 } & the relationship between employees and managers & 2 & $7-8$ \\
\cline { 2 - 4 } & control of the consumption & 2 & $9-10$ \\
\cline { 2 - 4 } & use of domestic production & 7 & $11-17$ \\
\hline
\end{tabular}

a) Validity: the validity of the questionnaires was determined based on the viewpoints of experts by content validity.

b) Reliability: the reliabilities of the variables was estimated by Cronbach's Alpha. The Cronbach's Alpha was estimated 0.902 for organizational agility and it was estimated 0.936 for resistive economy.

Also, based on the results, the values of $\mathrm{KMO}$ test for the variables of organizational agility and resistive economy were obtained 0.776 and 0.801 , respectively $(\mathrm{KMO}>0.05)$ and this indicates the sufficiency of sample and variables for analyzing.

\section{Hypotheses}

There is a significant relationship between the organizational agility and the organizational capacity of resistive economy in Isfahan's department of education.

There is a significant relationship between the organizational agility and the relationship between employees and managers in Isfahan's department of education.

There is a significant relationship between the organizational agility and the control of the consumption in Isfahan's department of education.

There is a significant relationship between the organizational agility and the use of domestic production in Isfahan's department of education.

Demographic characteristics of the staffs of Isfahan's department of education (gender, age, work experience, education, place of work) impact on their views about the realization of resistive economy and organizational agility.

How much are resistive economy and organizational agility among the staffs of Isfahan's department of education?

\section{Findings}

In order to investigate the significant relationship between the variables, correlation coefficient test was used and in order to investigate the significant difference between two independent groups (gender), t-test was used and in order to investigate the significant differences among several groups (education, work experience and ...), the analysis of variance was used and finally, one-sample t-test was used to clarify the situation of variables in the study? 


\subsection{Correlation coefficient test}

Table 3: Correlation between organizational agility and the components of resistive economy

\begin{tabular}{|l|l|c|c|}
\hline Indicators & Statistics of coefficient correlation & Level of significance \\
\hline & Organizational capacity & 0.486 & $* \star$ \\
\hline \multirow{3}{*}{ Organizational agility } & the relationship between employees and managers & 0.470 & $* \star$ \\
\cline { 2 - 4 } & control of the consumption & 0.398 & $\star \star \star$ \\
\cline { 2 - 4 } & use of domestic production & 0.461 & $* \star$ \\
\hline
\end{tabular}

$\star * *: P<0.01$

\subsection{Investigation of the hypotheses}

There is a significant relationship between the organizational agility and the organizational capacity of resistive economy.

According to table 3 , the value of correlation coefficient is 0.486 and the coefficient is significant at the level of 0.01 . This means that there is a significant relationship between the organizational agility and the organizational capacity of resistive economy. Given the positive value of coefficient, there is a positive relationship between the organizational agility and the organizational capacity.

There is a significant relationship between the organizational agility and the relationship between employees and managers in Isfahan's department of education.

According to table 3 , the value of correlation coefficient is 0.470 and the coefficient is significant at the level of 0.01 . This means that there is a significant relationship between the organizational agility and the relationship between employees and managers of resistive economy. Given the positive value of coefficient, there is a positive relationship between the organizational agility and the relationship between employees and managers.

There is a significant relationship between the organizational agility and the control of the consumption in Isfahan's department of education.

According to table 3 , the value of correlation coefficient is 0.398 and the coefficient is significant at the level of 0.01. This means that there is a significant relationship between the organizational agility and the control of the consumption of resistive economy. Given the positive value of coefficient, there is a positive relationship between the organizational agility and the control of the consumption.

There is a significant relationship between the organizational agility and the use of domestic production in Isfahan's department of education.

According to table 3 , the value of correlation coefficient is 0.461 and the coefficient is significant at the level of 0.01 . This means that there is a significant relationship between the organizational agility and the use of domestic production of resistive economy. Given the positive value of coefficient, there is a positive relationship between the organizational agility and the use of domestic production.

\subsection{T-test}

There are significant differences among the resistive economy and organizational agility of male and female employees in Isfahan's department of education.

Table 4: T-test results for investigating the significant difference between resistive economy and organizational agility in terms of gender

\begin{tabular}{|c|c|c|c|c|c|c|}
\hline & & & \multicolumn{2}{|c|}{ Levene test for equality of variance } & \multicolumn{2}{|c|}{ T-test for comparing the averages } \\
\hline & & average & F-statistic & Level of significance & T-statistic & Level of significance \\
\hline \multirow{2}{*}{ Resistive economy } & Female & 47.18 & \multirow{2}{*}{3.861} & \multirow{2}{*}{0.05} & \multirow{2}{*}{-0.258} & \multirow{2}{*}{0.797} \\
\hline & Male & 46.79 & & & & \\
\hline \multirow{2}{*}{ Organizational agility } & Female & 38.90 & \multirow{2}{*}{1.53} & \multirow{2}{*}{0.217} & \multirow{2}{*}{-1.32} & \multirow{2}{*}{0.187} \\
\hline & male & 37.61 & & & & \\
\hline
\end{tabular}

According to table 4 , since the significance level for both variables of resistive economy and organizational agility is more than 0.05 , the hypothesis that the averages are equivalent, is not rejected, it means there are no significant differences 
among the resistive economy and organizational agility of male and female employees in Isfahan's department of education. This means that the variable of gender doesn't play a role in the organizational agility and resistive economy.

\subsection{Analysis of variance}

There are significant differences among the resistive economy and organizational agility of different age groups of the employees in Isfahan's department of education.

Table 5: The results of the analysis of variance for investigating the significant difference between resistive economy and organizational agility in terms of age

\begin{tabular}{|l|l|c|c|c|c|c|}
\hline Variable & Source of change & Sum of squares & Degree of freedom & Mean square & F-statistic & Level of significance \\
\hline \multirow{3}{*}{ Resistive economy } & Between groups & 449.39 & 3 & 149.8 & 0.944 & 0.420 \\
\cline { 2 - 8 } & Within group & 44920.82 & 283 & 158.73 & & \\
\cline { 2 - 8 } & Sum & 45370.21 & 286 & & & \\
\hline \multirow{3}{*}{ Organizational agility } & Between groups & 743.60 & 3 & 247.87 & 3.95 & 0.000 \\
\cline { 2 - 8 } & Within group & 17765.13 & 183 & 62.77 & & \\
\cline { 2 - 8 } & Sum & 185082.73 & 286 & & & \\
\hline
\end{tabular}

According to table 5 , since the significance level is 0.420 for the variable of resistive economy and also it is more than 0.05 , the null hypothesis isn't rejected, it means that there are no significant differences among the resistive economy of different age groups of the employees. Also, according to table5, since the significance level is less than 0.05 for the variable of organizational agility, the null hypothesis is rejected, it means that there are significant differences among the organizational agility of different age groups of the employees.

There are significant differences among the resistive economy and organizational agility of the education of the employees in Isfahan's department of education.

Table 6: The results of the analysis of variance for investigating the significant difference between resistive economy and organizational agility in terms of education

\begin{tabular}{|l|l|c|c|c|c|c|}
\hline Variable & Source of change & Sum of squares & Degree of freedom & Mean square & F-statistic & Level of significance \\
\hline \multirow{3}{*}{ Resistive economy } & Between groups & 844.79 & 3 & 281.60 & 1.8 & 0.149 \\
\cline { 2 - 7 } & Within group & 44525.43 & 283 & 157.33 & & \\
\cline { 2 - 7 } & Sum & 45370.22 & 286 & & & \\
\hline \multirow{3}{*}{ Organizational agility } & Between groups & 121.42 & 3 & 40.43 & 0.6220 & 0.600 \\
\cline { 2 - 7 } & Within group & 18387.80 & 283 & 9764 & & \\
\cline { 2 - 7 } & Sum & 7318508 & 286 & & & \\
\hline
\end{tabular}

Also, according to table 6 , since the significance level for both variables of resistive economy and organizational agility is more than 0.05 , the null hypothesis isn't rejected, it means that there are no significant differences among the resistive economy and organizational agility of the employees with different education. It means that the variable of education doesn't play a role in the resistive economy and organizational agility.

There are significant differences among the resistive economy and organizational agility of the employees with different experiences in Isfahan's department of education.

Table 7: The results of the analysis of variance for investigating the significant difference between resistive economy and organizational agility in terms of work experience

\begin{tabular}{|l|l|c|c|c|c|c|}
\hline Variable & Source of change & Sum of squares & Degree of freedom & Mean square & F-statistic & Level of significance \\
\hline \multirow{3}{*}{ Resistive economy } & Between groups & 4561.18 & 3 & 1140.30 & 7.880 & 0.000 \\
\cline { 2 - 7 } & Within group & 40809.03 & 283 & 114.17 & & \\
\cline { 2 - 7 } & Sum & 45370.21 & 286 & & & \\
\hline \multirow{3}{*}{ Organizational agility } & Between groups & 265.39 & 3 & 66.35 & 1.03 & 0.39 \\
\cline { 2 - 7 } & Within group & 18243.34 & 283 & 64.69 & & \\
\cline { 2 - 7 } & Sum & 18508.73 & 286 & & & \\
\hline
\end{tabular}


According to table 7 , since the significance level is 0.000 for the variable of resistive economy and also it is less than 0.05 , the null hypothesis is rejected, it means that there are significant differences among the resistive economy of the employees with different work experiences. Also, according to table7, since the obtained value of significance is more than 0.05 for the variable of organizational agility, the null hypothesis isn't rejected, it means that there are no significant differences among the organizational agility of the employees with different work experiences.

There are significant differences among the resistive economy and organizational agility of the employees with different work places in Isfahan's department of education.

Table 8: The results of the analysis of variance for investigating the significant difference between resistive economy and organizational agility in terms of age

\begin{tabular}{|l|l|c|c|c|c|c|}
\hline Variable & Source of change & Sum of squares & Degree of freedom & Mean square & F-statistic & Level of significance \\
\hline \multirow{3}{*}{ Resistive economy } & Between groups & 45232.46 & 3 & 708.91 & 4.83 & 0.000 \\
\cline { 2 - 7 } & Within group & 41116.75 & 283 & 146.85 & & \\
\cline { 2 - 7 } & Sum & 45370.22 & 286 & & & \\
\hline \multirow{3}{*}{ Organizational agility } & Between groups & 318.30 & 3 & 53.05 & 0.82 & 0.56 \\
\cline { 2 - 8 } & Within group & 1890.43 & 283 & 64.97 & & \\
\cline { 2 - 8 } & Sum & 18508.73 & 286 & & & \\
\hline
\end{tabular}

According to table 8, since the significance level is 0.000 for the variable of resistive economy and also it is less than 0.05 , the null hypothesis is rejected, it means that there are significant differences among the resistive economy of the employees with different work places. Also, according to table8, since the obtained value of significance level is more than 0.05 for the variable of organizational agility, the null hypothesis isn't rejected, it means that there are no significant differences among the organizational agility of the employees with different work places.

\subsection{One-sample t-test}

In this test, the hypothesis about the average of population is investigated. According to Likert scale, the number 3 is considered as the average. This test was used to determine the level and situation of the factors in sample. If the significance level is less than 0.05 , the null hypothesis, which is the average of the variable in sample is equal to the hypothetical average (3), will be rejected.

Table 9: The result of the averages of variables

\begin{tabular}{|l|c|c|c|c|}
\hline Variable & Average & Standard deviation & t-statistic & Level of significance \\
\hline Organizational agility & 2.93 & 0.62 & -2.85 & 0.049 \\
\hline Resistive economy & 2.76 & 0.74 & 5.45 & 0.000 \\
\hline
\end{tabular}

According to table 9 , since the significance level is less than 0.05 for both variables of resistive economy and organizational agility, it can be concluded that there are significant differences between the obtained averages of both variables and hypothetical average (3). According to the average of organizational agility (2.93) and the average of resistive economy (2.76), it can be concluded that both variables of organizational agility and resistive economy among the employees of Isfahan's department of education are less than average.

\section{Discussion and Conclusion}

Resistive economy is not a theoretical concept just for the university, it is an applied economy. Resistive economy is not a slogan, it is an economic reality that its indicators are rooted in action not words. Inducing the thought of resistive economy is a clever measure to rescue the economic senior managers from the neglect created in the economy. Resistive economy needs to recognize the resources, both material and human resources, and use them. Resistive economy refers to the economic system of the nation or resistant social group who fights in accordance with their rights or the pursuit of political objectives which are right in the viewpoint of them. The more the economy of the nation or resistant social group help them in order to achieve the goals of resistance, the more resistance it is (Darvishzadeh and Beheshtifar, 2013). 
60.3 percent of sample (287 persons) was men. This difference can be seen from this issue that the most of the employees of the department of education are men. In terms of age group, most of them are in the 41 to 50 age group and the oldest of them is 48.4 years old. In the other words, half of them are in the middle-age group. In terms of education, $59 \%$ of them have bachelor's degree and finally, in term of work experience, $48 \%$ of them have more than 10 years of work experience and $32.8 \%$ of them have 6 to 10 years of work experience. In fact, it can be said that high percentage of the department of education's employees have high work experience.

The results of first hypothesis test which was done by Pearson correlation test, show that there is a significant relationship between the organizational agility and resistive economy among the employees of Isfahan's department of education. Also, these show that if the organization and its employees are agile, they can be effective in realization of resistive economy. These result are consistent with the results of the article by Abbas abad Arabi (2014) in which a conceptual model of resistive economy was provided by the approach of organizational agility. Based on this, the agile resistive economy can be reached by making the organization agile. Agility is an organizational capability that should be considered to achieve mentioned goals by the managers. In fact, an agile organization is an organization which has features such as innovation, flexibility and readiness to respond to environmental changes and also is very robust and stable in facing with problems and shortcomings. Such organization achieves mentioned features with the minimum cost and energy. So, if the organization is agile, it can help itself in realization of resistive economy.

The results of T-test and analysis of variance show that among the demographic variables (age, gender, education, work experience and work place), work experience and work place play roles in realization of resistive economy in the department of education, on the other word, it can be said that to realize the resistive economy in an organization, the gender, age group or higher education are not important and play no roles in it and all people with any gender, in any age group and with any higher education can try in realizing resistive economy but having high work experience has significant impact on it. As the demographic result showed, the most of the employees of the department of education had high work experience, this indicates that the large number of the department of education's employees can play significant roles in realizing resistive economy.

The results of one-sample t-test of the variables of organizational agility and resistive economy showed that in the department of education, the organizational agility and resistive economy was measured below average and this indicates that they are not good in this organization. In the current economic crisis that it seems necessary that the organization to be agile and the realization of resistive economy is more important, the managers and officials should try to better these two issues. The results of the test are consistent with the results of the study by Rahimian (2013) in which making the system of training agile in Hamadan technical and vocational training organization was studied. Its results showed that the organizational agility in this organization was below average. One of this reason can be that the managers of the department of education and technical and vocational training organization had no plan to make their organizations agile. But they should have a plan for organizational agility to realize resistive economy in their organizations.

The results of t-test indicated that there is no significant difference between the organizational agility of male and female employees of the department of education. This shows that the gender plays no roles in the organizational agility. In investigating the variable of age group, analysis of variance indicated that there are significant differences among the different age groups. It shows that the people in different age group have different organizational agility. In other words, the age plays a role in agility. Also, it was concluded that education plays no role in organizational agility. It shows that the agility of the employees don't relate to education. In investigating the work experience by the analysis of variance, it was observed that there is no significant relationship between the organizational agility and work experience. Its reason may be that the younger people who have less work experience can get organizational agility better, because they are more dynamic and also they have more intention to develop in compared with people who have more work experience and may retire soon. Also, it was concluded that the work place plays no role in organizational agility. It indicates that the organizational agility relates to the goals of organization and the responsibilities assigned to employees and since Iran's Ministry of education is centralized, if there is organizational agility in it, there will be organizational agility in all centers and it doesn't relate to the work place.

Given that this topic is new, up to now, no similar studies have been conducted on resistive economy in the organization or mentioned organizational factors in relation to its realization. The more research on resistive economy had identified resistive economy in different areas and conducted theoretically. It can be said that no proper applied study still have been conducted on the roles of organizational factors in realizing resistive economy.

Given the results and significant relationship between the organizational agility and the components of resistive economy, some recommendations are provided as follows:

- It is recommended to the officials of the department of education to educate and prepare their employees to 
enhance the organizational agility and improve their readiness to face with environmental changes.

- It is recommended to hold in-service courses to enhance the skills and abilities of the employees.

- It is recommended to the officials to try to buy domestic production.

- It is recommended to the officials to use internal resources of organization in today's economic conditions.

- It is recommended to the officials to familiarize the employees who have more decisive roles in reaching the goals of organization with resistive economy and encourage them to realize it.

- The employees who have more work experience are asked to help the employees who have less work experience to realize resistive economy.

Also, based on this study, it is suggested to interested researchers to study on the same fields of this study and study this topic on the department of education of other cities and wider community. In addition, it is suggested that the impact of educating resistive economy on organizational agility and educating organizational agility on resistive economy will be studied to expand the knowledge of resistive economy in future research.

\section{References}

Aghaei, M., Aghaei, R. (2014) "Conceptual model of organizational agility", Journal of Roshd -e- Fanavari, 10"t year, No. 43: 37-39.

Political information Center (2012) "The strategies of resistive economy in the department of education", .http://www.30a30.ir, code: 1465425 (13 $13^{\text {th }}$ August, 2012).

Torabzadeh jahromi, M.S., Sajadieh, A., Samiee nasab, M. (2013) "Investigating the dimensions and components of Islamic Republic of Iran's resistive economy in the viewpoint of Ayatollah Khamenei", Research Journal of Islamic Revolution, 32: 31-46.

Darvishzadeh, H., Bheheshtifar, M. (2013) "The productivity of human resources and resistive economy", Proceedings of National Conference of resistive economy with the approach of national production, Shahid Bahonar University of Kerman.

Rahimian, T. (2013) "Making the system of training agile in technical and vocational training organization (case study: Hamadan technical and vocational training organization)", proceedings of the book of technical and vocational training and employment in Iran, Tehran: publication of Iran technical and vocational training organization, $1^{\text {st }}$ publish.

Saboktakin, Ch., Jafari, H. (2013) "Investigation of social factors influencing the students' attitudes to lifestyle which is commensurate with resistive economy (case study: the students of Karaj City)", National Conference on the role of lifestyle role in resistive economy, Alborz Academic Center for Education, Culture and Research, $1^{\text {st }}$ period.

Abbasabad arabi, A., Babaeianpour, M., Fekri, R. (2014) "The conceptual model of resistive economy with an emphasis on agility model of organizations", Journal of Strategy, 71: 79-100.

Arabi, H., (2013) "Resistive economy according to the Supreme leader's remarks", Journal of Macro policy 2 (2): 9-25.

Supreme leader of Iran (2013) "The text imparted to the heads of three branches and the head of the Expediency Council by Iran's supreme leader" (18 thebruary 2013).

Yaghoubi, N., Shokri, A., Rahat delmordeh, M. (2012) "Structural enablers of organizational agility in the banking system", Journal of strategic management though, 1: 133-158. 